\title{
Biodegradation of lignin and nicotine with white rot fungi for the delignification and detoxification of tobacco stalk
}

Yulong Su ${ }^{1 \dagger}, \mathrm{He} \mathrm{Xian}^{2 \dagger}$, Sujuan Shi ${ }^{1,3}$, Chengsheng Zhang ${ }^{1}$, S. M. Nuruzzaman Manik', Jingjing Mao ${ }^{1}$, Ge Zhang ${ }^{1,3}$, Weihong Liao ${ }^{4}$, Qian Wang ${ }^{1 *}$ and Haobao Liü ${ }^{*}$

\begin{abstract}
Background: Tobacco stalk is one kind of abundant crop residues in China. The high lignification of tobacco stalk increases its reusing cost and the existing of nicotine will cause serious pollution. The biodegradation of lignocellulosic biomass has been demonstrated to be an environmental and economical approach for the utilization of plant stalk. Meanwhile, many nicotine-degrading microorganisms were found in nature. However, microorganisms which could degraded both nicotine and lignin haven't been reported. Therefore, it's imperative to find some suitable microorganisms to break down lignin and simultaneously remove nicotine in tobacco stalk.

Results: The nicotine in tobacco stalk could be degraded effectively by Trametes versicolor, Trametes hirsute and Phanerochaete chrysosporium. The nicotine content in tobacco stalk was lowered to below $500 \mathrm{mg} / \mathrm{kg}$ (a safe concentration to environment) after 10 days of fermentation with Phanerochaete chrysosporium and Trametes versicolor, and 15 days with Trametes hirsute. The degradation rate of lignin in the fermented tobacco stalk was 37.70, 51.56 and 53.75\% with Trametes versicolor, Trametes hirsute and Phanerochaete chrysosporium, respectively. Meanwhile, 24.28\% hemicellulose was degraded by Phanerochaete chrysosporium and 28.19\% cellulose was removed by Trametes hirsute. Through the enzyme activity analysis, the main and highest ligninolytic enzymes produced by Phanerochaete chrysosporium, Trametes hirsute and Trametes versicolor were lignin peroxidase $\left(88.62 \mathrm{U} \cdot \mathrm{L}^{-1}\right)$, manganese peroxidase $\left(100.95 \mathrm{U} \cdot \mathrm{L}^{-1}\right)$ and laccase $\left(745.65 \mathrm{U} \cdot \mathrm{L}^{-1}\right)$. Meanwhile, relatively high and stable cellulase activity was also detected during the fermentation with Phanerochaete chrysosporium, and the highest endoglucanase, exoglucanase and filter paper enzyme activities were $0.38 \mathrm{U} \cdot \mathrm{mL}^{-1}, 0.45 \mathrm{U} \cdot \mathrm{mL}^{-1}$ and $0.35 \mathrm{U} \cdot \mathrm{mL}^{-1}$, respectively. Moreover, the products in the fermentation of tobacco stalk with $P$. chrysosporium were identified with GC-MS, besides the chemicals produced in the degradation of lignin and nicotine, some small molecular valuable chemicals and fatty acid were also detected.

Conclusions: Our study developed a new method for the degradation and detoxification of tobacco stalk by fermentation with white rot fungi Phanerochaete chrysosporium and Trametes hirsute. The different oxidative enzymes and chemical products detected during the degradation indicated a possible pathway for the utilization of tobacco stalk.
\end{abstract}

Keywords: Tobacco stalk, Nicotine degradation, Delignification, Phanerochaete chrysosporium, Lignocellulolytic enzymes

\footnotetext{
*Correspondence: wangqian_2000zb@163.com; Liuhaobao@caas.cn

${ }^{\dagger}$ Equal contributors

${ }^{1}$ Key Laboratory of Tobacco Biology and Processing, Tobacco Research

Institute, Chinese Academy of Agricultural Sciences, Qingdao 266101,

People's Republic of China

Full list of author information is available at the end of the article
} 


\section{Background}

Tobacco is an important cash crop in China and has been planted in many farming areas. It has been estimated that about 3.2 million tons of tobacco stalk were produced annually in China [1]. The reusing of tobacco stalk is costly due to its high lignification. Most of tobacco stalk is discarded in the field directly and the nicotine in tobacco stalk can easily permeate into the soil, affecting its ecological structure and also polluting the ground water. It is reported that the average nicotine content in tobacco stalk is up to $3800 \mathrm{mg} / \mathrm{kg}$ [2] and the nicotine-containing waste would be classified as "toxic and hazardous", when the concentration of nicotine exceeds $500 \mathrm{mg} / \mathrm{kg}$ dry weight [3]. Therefore, it is imperative to remove nicotine from tobacco stalk so as to make better utilization of tobacco stalk.

Significant progresses have been made in the utilization of tobacco stalk such as making fiberboard, tobacco sheet, acticarbon or extracting chemicals [4-7]. However, all of these methods were deficient due to the terrible pollution on the environment or the high cost, and it is necessary to explore new approaches to the safe and sustainable utilization of tobacco stalk. The biodegradation of lignocellulosic biomass has been demonstrated to be an environmental-friendly and economical way for the reusing of plant stalk [8]. It is already shown that fungi belonged to Moniliales Gliocephalias sp. [9] and Aspergillus sp. [10] could degrade lignin in tobacco stalk. However, the microbes that could be used for the biodegradation of tobacco stalk were still limited due to the high lignification and the existing of nicotine. Though many microorganisms have been demonstrated to be able to degradate lignin and nicotine separately $[11,12]$, microorganisms which could degradate the both haven't been reported.

This study aimed to screen anti-nicotine microorganisms for the degradation of tobacco stalk, and explore their degradation characteristics. The research will provide a better way for the innocent treatment of tobacco stalk.

\section{Results and discussion}

\section{Effect of fungi fermentation on nicotine degradation in} tobacco stalk

The concentration of nicotine in tobacco stalk was $1900 \mathrm{mg} / \mathrm{kg}$ in this study (Fig. 1). Nicotine has been defined as one kind of the toxic and hazardous chemicals in tobacco wastes [13]. It can contaminate ground water when the concentration exceeds $500 \mathrm{mg} / \mathrm{kg}$ in dry weight. Therefore, it is necessary to prevent the contamination of nicotine during the biodegradation of tobacco stalk.

Nicotine concentration analysis showed that all the fungi selected could efficiently degradate nicotine (Fig. 1). For P. chrysosporium and T.versicolor, the concentration

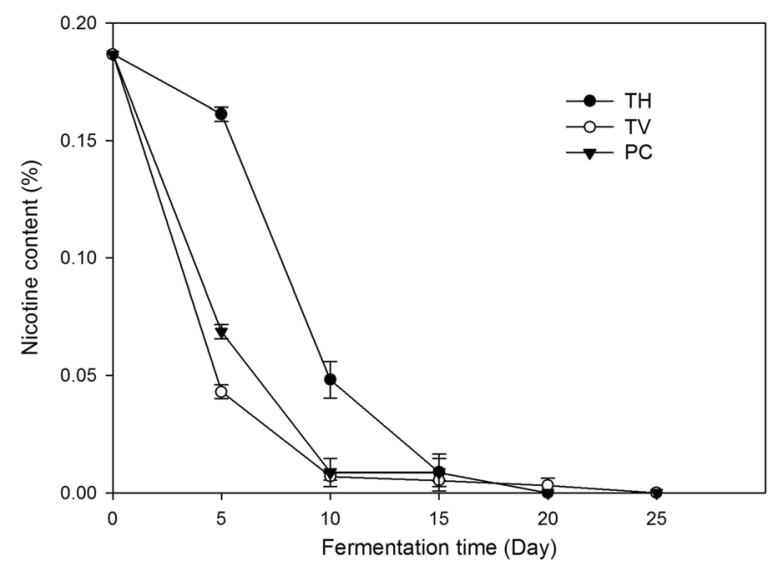

Fig. 1 The content of nicotine in tobacco stalk when fermentation with Phanerochaete chrysosporium, Trametes versicolor and Trametes hirsute in solid state. The culture temperature was $28{ }^{\circ} \mathrm{C}$ and the

relative humidity was $80 \%$, the nicotine content was detected every 5 days until 25 days after inoculation

of nicotine in tobacco stalk remained lower than $500 \mathrm{mg} / \mathrm{kg}$ after 10 days of fermentation. For T. hirsute, it is found that nicotine degradation was accelerated from day 10-15 after inoculation. The nicotine content was less than $550 \mathrm{mg} / \mathrm{kg}$ after 15 days fermentation. No residual nicotine was detected in fermented aqueous extracts after 25 days of incubation in all the fungi culture. To our best knowledge, this is the first study showing that nicotine can be degraded by $P$. chrysosporium, $T$. versicolor and $T$. hirsute and making the bio-degradation of nicotine. Lac can oxidize phenolic compounds directly, while all the three enzymes can oxidize divers non-phenolic aromatic compounds with the help of mediators [14], which would be helpful to the degradation of nicotine.

\section{Effect of fungi fermentation on lignocelluloses degradation in tobacco stalk}

It is shown that in the nicotine degradation process, at least 10-15 days of fermentation is necessary to ensure the degradation of nicotine in tobacco stalk to a safe concentration. The lignocelluloses were also monitored during the process to verify the selective degradation of lignin in tobacco stalk with three white rot fungi selected.

The untreated tobacco stalk used in this study was composed of $40.28 \%$ hemicellulose, $30.22 \%$ cellulose, $21.06 \%$ lignin and others. The lignocelluloses biodegradation in tobacco stalk caused by three white rot fungi ( $P$. chrysosporium, $T$. hirsute and $T$. versicolor) are listed in Table 1. The result showed that the lignocelluloses decreased gradually with increasing fermentation time. A significantly decrease of hemicellulose was observed in $P$. chrysosporium (24.28\%), and cellulose was 
Table 1 Changes in lignocelluloses content of tobacco stalk treated with white rot fungi strains during solid state fermentation (dry matter basis)

\begin{tabular}{|c|c|c|c|c|c|c|c|}
\hline Strains & $\begin{array}{l}\text { Fermentation } \\
\text { period (days) }\end{array}$ & $\begin{array}{l}\text { Cellulose } \\
\text { content (\%) }\end{array}$ & $\begin{array}{l}\text { Cellulose } \\
\text { degradation (\%) }\end{array}$ & $\begin{array}{l}\text { Hemicellulose } \\
\text { content (\%) }\end{array}$ & $\begin{array}{l}\text { Hemicellulose } \\
\text { degradation (\%) }\end{array}$ & $\begin{array}{l}\text { Lignin content } \\
(\%)\end{array}$ & $\begin{array}{l}\text { Lignin degradation } \\
(\%)\end{array}$ \\
\hline Control $^{a}$ & & 30.22 & & 40.28 & & 21.06 & \\
\hline \multirow[t]{4}{*}{ P.chrysosporium } & 9 & 26.96 & 10.79 & 37.32 & 7.35 & 11.92 & 43.40 \\
\hline & 11 & 26.22 & 13.24 & 35.6 & 11.62 & 11.74 & 44.25 \\
\hline & 13 & 25.96 & 14.10 & 33.28 & 17.38 & 11.68 & 44.54 \\
\hline & 15 & 22.32 & 22.17 & 30.5 & 24.28 & 10.94 & 53.75 \\
\hline \multirow[t]{4}{*}{ T. hirsute } & 9 & 28.18 & 6.75 & 37.28 & 7.45 & 12.96 & 38.46 \\
\hline & 11 & 24.22 & 19.85 & 35.54 & 11.77 & 12.5 & 40.65 \\
\hline & 13 & 23.64 & 21.77 & 35.06 & 12.96 & 11.88 & 43.59 \\
\hline & 15 & 21.7 & 28.19 & 34.18 & 15.14 & 10.2 & 51.57 \\
\hline \multirow[t]{4}{*}{ T. versicolor } & 9 & 28.88 & 4.43 & 38.46 & 4.52 & 15.88 & 24.60 \\
\hline & 11 & 28.78 & 4.77 & 37.36 & 7.25 & 15.74 & 25.26 \\
\hline & 13 & 27.08 & 10.39 & 36.36 & 9.73 & 15.26 & 27.54 \\
\hline & 15 & 26.24 & 13.17 & 36.02 & 10.58 & 13.12 & 37.70 \\
\hline
\end{tabular}

control $^{\mathrm{a}}$ : The data in bold was the control, the initial contents of cellulose, hemicellulose and lignin

degraded by $28.19 \%$ after 15 days fermentation with $T$. hirsute. Almost the same amount of lignin was degraded by three white rot fungi from $9-15$ days, the maximum lignin reduction 53.75 and $51.56 \%$ were observed in $P$. chrysosporium and $T$. hirsute, respectively, but only $37.70 \%$ lignin in tobacco stalk was removed by $T$. versicolor.

In our study, hemicellulose was significantly degraded by $P$. chrysosporium and cellulose was significantly degraded by $T$. hirsute, and both of the two fungi showed relative higher lignin degradation rate. This is in accordance with previous reports that selective white-rot fungi utilized hemicellulose and/or cellulose to support their growth [15]. For lignin degradation of tobacco stalk, a maximum of $37.60 \%$ lignin degradation rate was reached on day 7 by Aspergillus sp. [10] and 39.39\% on day 30 by Moniliales Gliocephalias sp. [9], meanwhile the enzyme activities were not investigated. The steam explosion pretreatment of the tobacco stalk may be benefit to get a relatively higher lignin degradation rate [16].

The selective degradation of lignin in tobacco stalk is important for the reusing of cellulose in tobacco stalk. The selectivity was evaluated by comparing the relative degradation rate for lignin and cellulose. The percentages of lignin degradation obtained in this study were higher than cellulose, which indicates the three fungal strains could be used in the delignification of tobacco stalk.

Water-soluble and ester-soluble chemicals after fermentation with $P$. chrysosporium

With the development of synthetic biology, more and more valuable chemical products were found and qualified. Tobacco stalk is rich in lignin and nicotine and identification of the fermented products and the intermediates may be helpful for finding valuable biobased chemicals. In this study, P. chrysosporium was shown to degrade the tobacco stalk efficiently. Moreover, it could secrete various enzymes. Therefore, the products in the degradation of tobacco stalk with $P$. chrysosporium were qualified. The total ion chromatographs corresponding to the compounds extracted with ethyl acetate and water from the supernatants of the fermentation stalk by $P$. chrysosporium were analyzed.

According to the degradation pathway of the nicotine and lignin $[17,18]$, some intermediates during the degradation of nicotine such as myosmine, cotinine, Nmethyl nicotinamide, $\mathrm{N}$-methylpyrrolidone, pyridine, 2,3'-dipyridyl, nicotinyl alcohol and niacin were detected in the culture of $P$. chrysosporium (Table 2). Meanwhile, some products from the degradation of lignin were also detected in the culture of $P$. chrysosporium such as 2furancarboxaldehyde, 5-methyl, 2-furancarboxaldehyde, 5-(hydroxymethyl), vanillin, benzenemethanol, 3, 4dimethoxy (Table 2). The detection of these chemical products further proves the nicotine-degrading ability of $P$. chrysosporium. Besides the chemicals produced in the degradation of lignin and nicotine, some small molecular valuable chemicals and fatty acid were also detected in cultures of $P$. chrysosporium. Acetoin and acrylic acid were measured in water extractions. Ethyl propionate and propyl acetate were detected in ethyl acetate extractions. Palmitic acid was found in both of them.

The detection of lignin and nicotine degradation intermediates further proved the lignin and nicotine degradation ability of $P$. chrysosporium. It has been demonstrated 
Table 2 The main components in the cultures of P. chrysosporium $(80 \% \mathrm{~W})$ grew on tobacco stalk during solid-state fermentation

\begin{tabular}{|c|c|c|c|}
\hline The classification of the fermentation products & Retain time (min) & Solvent & Name \\
\hline \multirow[t]{6}{*}{ Nicotine degradation products } & 6.99 & aqueous phase & Myosmine \\
\hline & 17.63 & aqueous phase & Cotinine \\
\hline & 17.75 & aqueous and ethyl acetate phase & Nicotinyl alcohol \\
\hline & 19.51 & aqueous phase & 3-Hydroxypyridine \\
\hline & 22.01 & aqueous phase & Nicotinic acid \\
\hline & 23.62 & aqueous phase & Pyridine \\
\hline \multirow[t]{3}{*}{ Lignin degradation products } & 20.19 & aqueous phase & 5-Hydroxymethylfurfural \\
\hline & 21.20 & aqueous phase & Veratryl alcohol \\
\hline & 20.75 & ethyl acetate phase & Vanillin \\
\hline \multirow[t]{5}{*}{ Small and high molecular organic } & 3.03 & ethyl acetate phase & Ethyl propionate \\
\hline & 3.15 & ethyl acetate phase & Propyl acetate \\
\hline & 7.91 & aqueous phase & Acetoin \\
\hline & 11.71 & aqueous phase & Acrylic acid \\
\hline & 23.98 & aqueous phase and ethyl acetate phase & Palmitic acid \\
\hline
\end{tabular}

by Li [19] and Meng [11] that demethylation pathway is the main nicotine degradation pathway performed by fungi. In our study, some intermediates of demethylation pathway were detected in the culture of P. chrysosporium, such as cotinine, N-methylmyosmine and pseudooxynicotine. In addition, some different intermediates such as 3Pyridinol, nicotinyl alcohol and niacin which may be the degradation intermediates were also detected which hint a new nicotine degradation pathway may be present in $P$. chrysosporium. Moreover, the detection of small molecular chemicals and fatty acid provides a possible pathway for production of biobased chemicals by fermentation with tobacco stalk. The degradation pathway of nicotine and the concentration of the products in the degradation of tobacco stalk with $P$. chrysosporium need further research.

\section{Enzyme activities produced during solid state fermentation of tobacco stalk}

Enzyme activities are important characteristics for the degradation of biomass, moreover, the produced enzymes can also be used in various applications. In this study, the detection of enzyme activities were carried out for 25 days to identify the highest enzyme activities. Ligninolytic and cellulolytic enzymes activities were monitored in the degradation process to estimate their potential application in lignocellulolytic enzymes production.

\section{Ligninolytic enzyme during solid state fermentation of tobacco stalk}

Lac, LiP and MnP are three kinds of common lignin peroxides enzymes secreted in the degradation of lignocelluloses biomass. It was found that different ligninolytic enzymes were secreted by different fungi when fermentation with tobacco stalk. However, not all of the ligninolytic enzymes were produced by a specific fungus.

The highest activity of $\mathrm{MnP}\left(100.95 \mathrm{U} \cdot \mathrm{L}^{-1}\right)$ was observed in $T$. hirsute at an early stage after inoculation (Fig. 2). This result further proved that MnP is a lignin attack enzyme produced by basidiomycetes in the initial stage of lignin degradation [20]. On the other hand, a relatively higher Lac activity $\left(254.72 \mathrm{U} \cdot \mathrm{L}^{-1}\right)$ was also observed with $T$. hirsute. Lip was found play an important role during the degradation of tobacco stalk for $P$. chrysosporium and the highest LiP activity $\left(88.62 \mathrm{U} \cdot \mathrm{L}^{-1}\right)$ was achieved at $15 \mathrm{~d}$ after inoculation (Fig. 2). The highest activity of Lac $\left(745.65 \mathrm{U} \cdot \mathrm{L}^{-1}\right)$ was achieved at $15 \mathrm{~d}$ after inoculation with $T$. versicolor (Fig. 2).

All of these ligninolytic enzymes may be potentially applied in biobleaching, biopulping and the biodegradation of aromatic environmental pollutants [21]. And fermentation of lignocelluloses by fungi is becoming an economical way for the production of these ligninolytic enzymes. In this study, Lac activity detected in $T$. versicolor was at a higher level compared with Wang et al. report $\left(633.3 \mathrm{U} \cdot \mathrm{L}^{-1}\right)$ [22] emphasizing the necessity to use tobacco stalk as substrate for the production of Lac.

\section{Cellulolytic enzyme produced during the solid state fermentation of tobacco stalk}

Endoglucanase (E.C.3.2.1.4) (CMCase), exoglucanase (E.C.3.2.1.91) (avicelase) and filter paper enzyme (FPA) are the main cellulase produced in the degradation of cellulose. It was observed that all the fungi tested could secret a considerable amount of cellulolytic enzymes (Fig. 3).

The highest CMCase $(0.51 \mathrm{U} / \mathrm{mL})$ and avicelase activity $(0.51 \mathrm{U} / \mathrm{mL})$ were observed in $T$. versicolor and the 


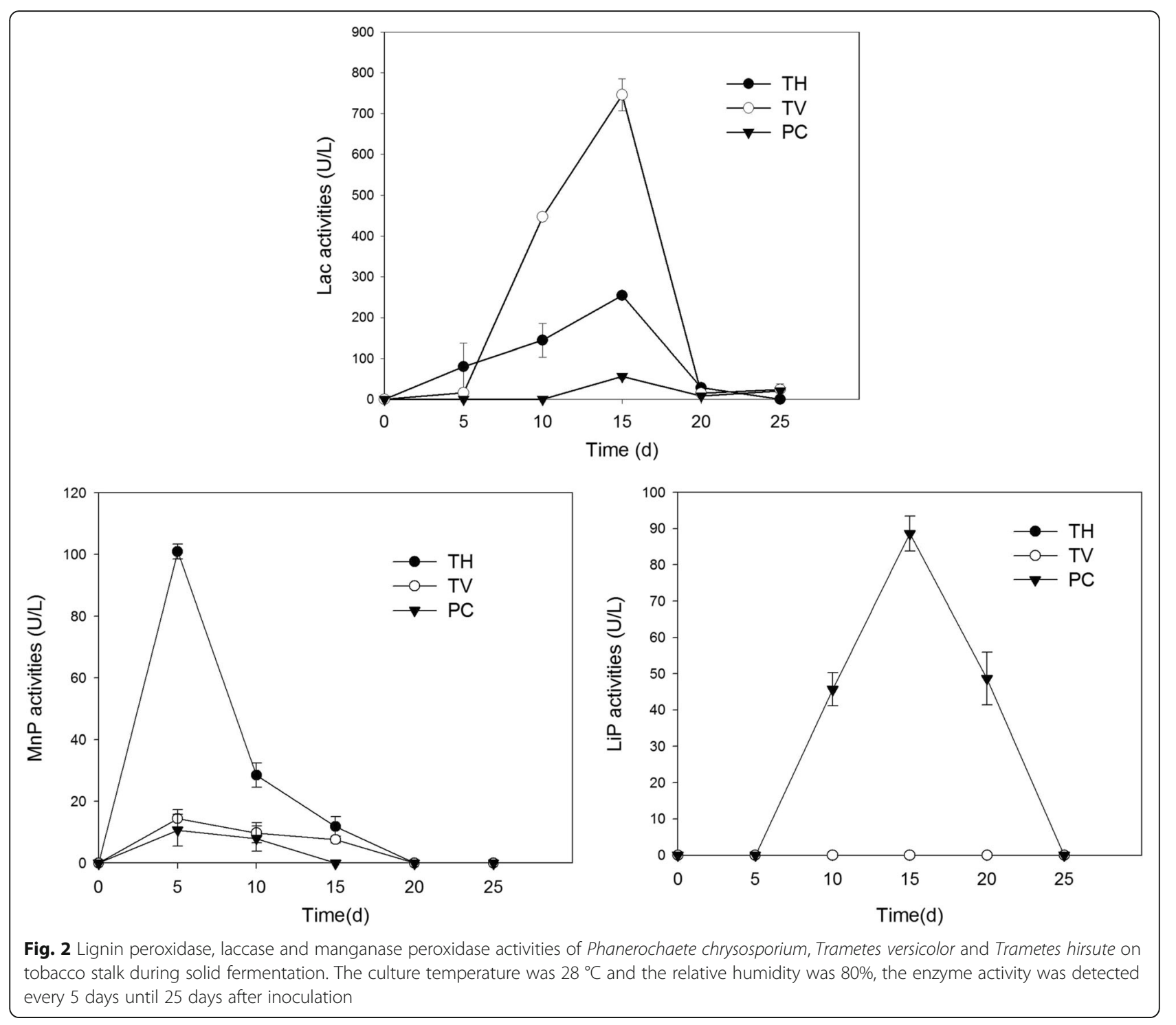

highest FPA activity was observed in T. hirsute (0.43 U/ $\mathrm{mL}$ ). Though the highest cellulase activities were detected in T. hirsute or T. versicolor, their enzyme activities were unstable compared with $P$. chrysosporium. Cellulolytic enzyme activities in T. hirsute and T. versicolor were sharply decreased at 20 days after inoculation and were significantly lower than $P$. chrysosporium (Fig. 3). Overall, P. chrysosporium could produce cellulase more consecutively, suggesting that it is more suitable for the production of cellulase by fermentation with tobacco stalk.

It can also conclude that the cellulolytic enzymes production of fungi strains was influenced by substrate. FPA was demonstrated to be the dominant cellulase produced by $T$. versicolor when fermentation with sorghum husks [23] and the highest CMCase activity was observed in $T$. versicolor when fermentation with wheat stalk [24]. However, almost the same amount of CMCase $(0.48 \mathrm{U} / \mathrm{mL})$ and avicelase $(0.51 \mathrm{U} / \mathrm{mL})$ was produced by $T$. versicolor when fermentation with tobacco stalk (Fig. 3). T. hirsute showed a relatively higher CMCase enzyme activity when fermentation with paddy straw [25]. While the relatively higher FPA activity was observed in $T$. hirsute when using tobacco stalk as substrate (Fig. 3).

The enzymes secreted from the strains undergo a sharp decrease in activity in the late stages of the experiments. When a fungus was inoculated to the tobacco stalk, various enzymes were secreted to degradate the tobacco stalk. Even in the degradation of lignin, laccase, Lip and Mnp are the representative enzymes but not the whole enzymes in the degradation process. Furthermore, 


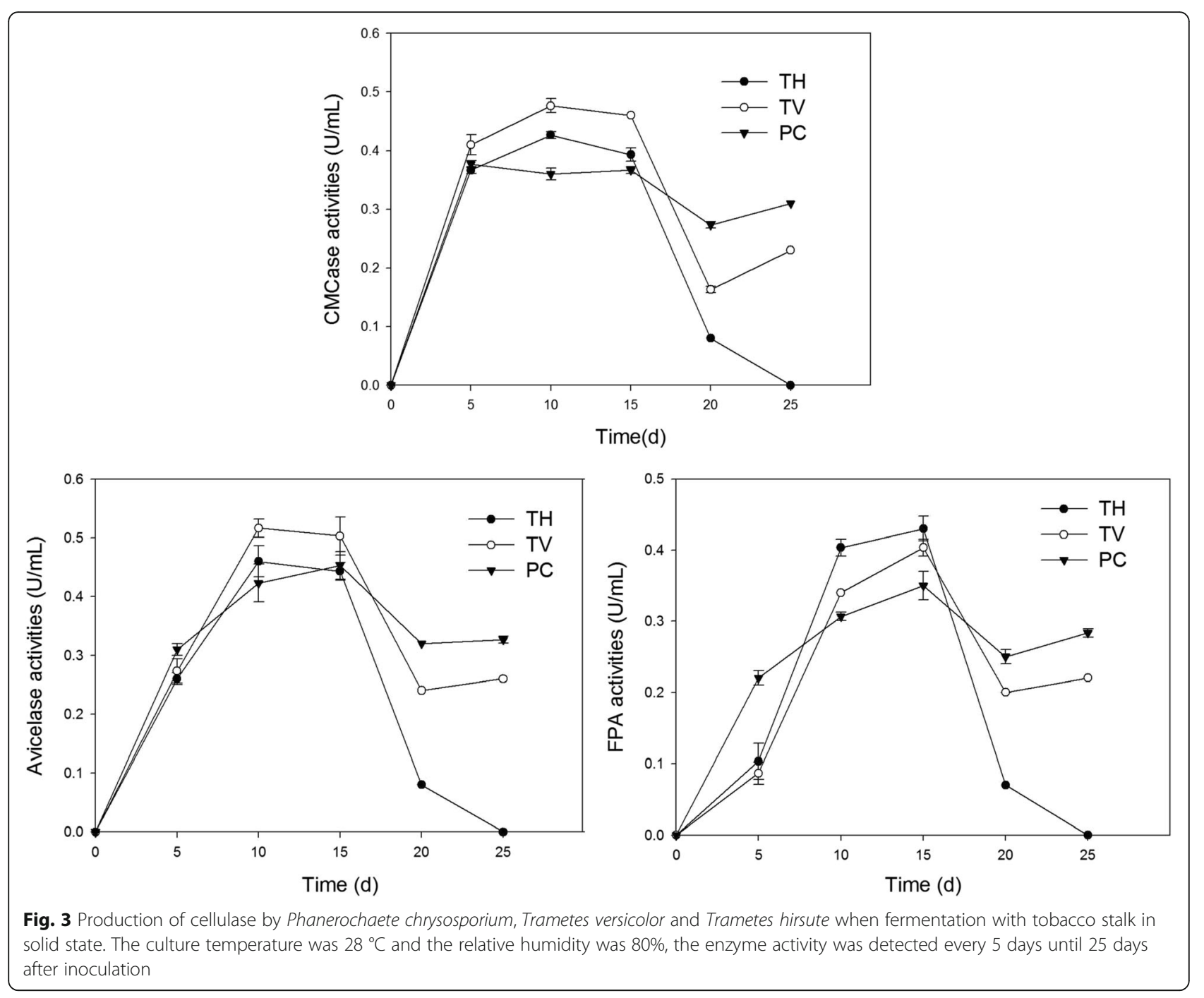

different enzymes might play different roles in different process. Therefore, to consider the production of enzymes using tobacco stalk in our subsequently research, the characteristic of the enzymes would be investigated including the stability and the inhibitor of the enzymes etc.

\section{Relationship between enzyme producing and lignocelluloses degradation}

It could be concluded that specific ligninolytic enzymes were produced by different fungi during the fermentation of tobacco stalk and lead to the different degradation efficiencies of lignin. LiPs are able to oxide the lignin compounds directly via long-range electron transfer and was considered as key enzymes in the degradation of lignin especially for $P$. chrysosporium [26]. The highest lignin degradation ability of $P$. chrysosporium is in accordance with the highest LiP activity detected in $P$. chrysosporium. The large molecular weight of Lac makes it difficult to penetrate into the lignocelluloses, and Lac was reported to play an important role in the initial stage of lignocellulose degradation [27]. That's the reason why $T$. versicolor showed highest Lac activity but had lower lignin degradation efficiency.

\section{Conclusion}

The nicotine in tobacco stalk could be degraded to a safe level after 15 days of fermentation with the three white rot fungi Phanerochaete chrysosporium, Trametes versicolor and Trametes hirsute. Phanerochaete chrysosporium is suitable for the degradation of lignin in tobacco with $53.75 \%$ lignin reduction after 15 days fermentation. A considerable amount of laccase $\left(745.65 \mathrm{U} \cdot \mathrm{L}^{-1}\right)$ was produced by Trametes versicolor and a relatively higher cellulase was secreted by Phanerochaete chrysosporium during the degradation of tobacco stalk. Furthermore, the products and intermediate in the degradation of tobacco stalk with $P$. chrysosporium were qualified. Enzyme activity detection 
results and the products had indicated a new approach for the reusing of tobacco stalk.

\section{Methods}

\section{Tobacco stalk and strains}

The tobacco stalk was obtained from the tobaccoplanting area of Zhucheng Shandong province in China. The stalk was dried at $80{ }^{\circ} \mathrm{C}$ for $12 \mathrm{~h}$, ground and sieved through a 40 mesh size sieve and then stored in valve bag for further treatment. Tobacco stalk was autoclaved at $121{ }^{\circ} \mathrm{C}$ for $20 \mathrm{~min}$ prior to inoculation with strains.

Four fungi Phanerochaete chrysosporium, Trametes versicolor [28], Trametes hirsute [29], Aspergillus sp. which were widely used in the biodegradation of other crop straw and other screened strains were used in this research. Their capacity to utilize the tobacco stalk as the sole carbon resource had been screened. Based on the preliminary results, $P$. chrysosporium, $T$. versicolorand $T$. hirsute were chosen for the further research of degradation of lignin and nicotine. The strains were provided by Chengsheng Zhang, a researcher belongs to Tobacco Research Institute of Chinese Academy of Agricultural Sciences, Key Laboratory of Tobacco Pest Monitoring Controlling \& Integrated Management, State Tobacco Monopoly Bureau.

Solid state fermentation of tobacco stalk with selected fungi Solid state fermentation was carried to verify the tobacco stalk degradation efficiency of the strains selected. $10 \mathrm{~g}$ dried tobacco stalk was added into a $100 \mathrm{~mL}$ conical flask with $40 \mathrm{~mL}$ distilled water and autoclaved at $121{ }^{\circ} \mathrm{C}$ for $20 \mathrm{~min}$. The fungal organisms were precultured on PDA (Potato Dextrose Agar) medium for 2 weeks, and two agar plugs $(5 \mathrm{~mm}$ in diameter) of the overgrown plates were used to inoculate solid-state microcosms. The flasks were incubated at $28{ }^{\circ} \mathrm{C}$ for $25 \mathrm{~d}$ without light. All the fungi were treated identically and the conical flask with no inoculation was used as control.

\section{Determination of the degradation of tobacco stalk}

The tobacco stalk is mainly composed of lignocellulose and nicotine. Meanwhile, lignocellulose is composed of lignin, cellulose and hemicellulose, among which the abundance of lignin is higher than most of the other biomass. The content of lignin, cellulose and hemicellulose were detected in this study to verify the tobacco stalk degradation efficiency.

\section{Determination of nicotine in tobacco stalk}

The content of nicotine in tobacco stalk was determined after incubation with an interval of 5 days by the method described by Wang et al. [30] The fermentation was carried out in quintuplicate, and every group was sampled on day $5,10,15,20$ and 25 , respectively, to make sure that the whole microenvironment was not disturbed. The fermentation product was extracted with hydrochloric acid $(0.5 \mathrm{~mol} / \mathrm{L})$ at a ratio of $0.05 \mathrm{~g} / 25 \mathrm{~mL}$, then mixed with active carbon $(0.25 \mathrm{~g})$ for $5 \mathrm{~min}$ and filtered through filter paper. The absorptions of the extraction were monitored by a UV-vis spectrophotometer (UV 2550) at given wavelengths (236, 259 and $282 \mathrm{~nm}$ ). The content of nicotine in tobacco stalk was calculated by the following formula:

$$
\begin{aligned}
\text { Nicotine }(\%)=1.059 & \times\left[\mathrm{A}_{259}-0.5 \times\left(\mathrm{A}_{236}+\mathrm{A}_{282}\right)\right] \\
& \times 100 \times 100 / \mathrm{W} \times(1-\mathrm{Water} \%) \\
& \times 34.3 \times 1000
\end{aligned}
$$

In the formula, 1.059 is the compensation coefficient; A259, A236 and A282 are the absorbance values of reaction system at 259, 236 and $282 \mathrm{~nm}$; W is the weight of sample; 34.3 is the specific extinction coefficient of nicotine.

\section{Determination of lignocelluloses in tobacco stalk}

Every fungus was inoculated into four groups of conical flasks which were sampled at 9, 11, 13, $15 \mathrm{~d}$ after inoculation, respectively, each group was tripled. The treated tobacco stalk was extracted with $50 \mathrm{~mL}$ distilled water at $200 \mathrm{rpm}$ at $28{ }^{\circ} \mathrm{C}$ for $2 \mathrm{~h}$. The suspension was filtered through filter paper, and the solid residue was collected and dried at $50{ }^{\circ} \mathrm{C}$ for 2 days to a constant weight. The fermented dried residue was milled in order to obtain homogeneous samples. A modified quantitative analysis program [31] was used to determine the content of lignocelluloses in tobacco stalk.

First, $0.5 \mathrm{~g}$ dried residue was autoclaved with $50 \mathrm{~mL}$ neutral detergent at $105{ }^{\circ} \mathrm{C}$ for $1 \mathrm{~h}$, then filtered through sand core crucible, the solid residue was washed by distilled water $(50 \mathrm{~mL})$ and acetone $(50 \mathrm{~mL})$ and weighed (W1) after dried at $80{ }^{\circ} \mathrm{C}$ for $12 \mathrm{~h}$. Second, the residual in the first procedure was autoclaved with $50 \mathrm{~mL}$ hydrochloric acid $(2 \mathrm{~mol} / \mathrm{L}, 50 \mathrm{~mL})$ at $105{ }^{\circ} \mathrm{C}$ for $1 \mathrm{~h}$. After being cooled, the washing and drying step was repeated as described above and the solid residue was weighed (W2). Subsequently, the residual was hydrolyzed with $72 \% \mathrm{H}_{2} \mathrm{SO}_{4}(45 \mathrm{~mL})$ for $3 \mathrm{~h}$, then $45 \mathrm{~mL}$ distilled water was added and keep at room temperature for $12 \mathrm{~h}$. The mixture was filtered and the residues was washed and dried as mentioned in the first step, then the third weigh (W3) was got. At last, the dried residue was calcined in a muffle burner at $550{ }^{\circ} \mathrm{C}$ for $3 \mathrm{~h}$; the ash product was weighed (W4) after being cooled in the vacuum dryer. The contents of hemicellulose, cellulose and lignin were calculated by the following formulas: 


$$
\begin{aligned}
& \text { Hemicellulose }(\%)=(\mathrm{W} 1-\mathrm{W} 2) / 0.5 \times 100 \% \\
& \text { Cellulose }(\%)=(\mathrm{W} 2-\mathrm{W} 3) / 0.5 \times 100 \% \\
& \text { Lignin }(\%)=(\mathrm{W} 3-\mathrm{W} 4) / 0.5 \times 100 \%
\end{aligned}
$$

\section{Determination of fermentation products with GC-MS}

To further characterise the lignin and nicotine degradation ability of the chosen fungi, fermentation products of $P$. chrysosporium which was more efficiently in the degradation of tobacco stalk was determined. The cultures were extracted by water and ethyl acetate respectively at a ratio of $1 \mathrm{~g} / 10 \mathrm{~mL}$ for $2 \mathrm{~h}$ with a rotation of $180 \mathrm{rpm} / \mathrm{min}$. Then the mixture was centrifuged at 12,000 rpm for $10 \mathrm{~min}$ and the supernatant was collected for GC-MS analysis.

Products characterization was carried out by capillary GC-MS using an Agilent 5975C system chromatograph. A HP-INNOWAX capillary column $(30 \mathrm{~m} \times 0.25 \mathrm{~mm} \times$ $0.25 \mu \mathrm{m}$, Agilent, Palo Alto, CA, USA) was used, with helium as the carrier gas at a flow rate of $1 \mathrm{~mL} \cdot \mathrm{min}^{-1}$. The following oven temperature program was carried out: $50{ }^{\circ} \mathrm{C}$ for $1 \mathrm{~min}$, increase of $20{ }^{\circ} \mathrm{C} / \mathrm{min}$ to $120{ }^{\circ} \mathrm{C}$, then programmed from 120 to $250{ }^{\circ} \mathrm{C}$ at $25{ }^{\circ} \mathrm{C} / \mathrm{min}$, where it was held for $5 \mathrm{~min}$. The injector temperature was maintained at $250{ }^{\circ} \mathrm{C}$; ion source temperature $230{ }^{\circ} \mathrm{C}$; EI $70 \mathrm{eV}$; mass range $35-300 \mathrm{~m} / \mathrm{z}$. A suitable amount of sample was injected in split injection mode with a 20:1 split ratio. Peak identification was based on the relative retention time and total ion mass spectral comparison with the external standard.

\section{Assay of enzyme activities during the degradation of tobacco stalk}

Enzyme was extracted by sodium acetate $(10 / 1, \mathrm{v} / \mathrm{w})$ at $\mathrm{pH} 6.5$ and agitated on a rotary shaker at $180 \mathrm{rpm}$ for $30 \mathrm{~min}$. The extraction was filtered using Whatman filter paper, the filtrate was used for enzyme assay.

\section{Assay of ligninolytic enzyme activities during the degradation of tobacco stalk}

Lignin peroxidase (LiP) (EC 1.11.1.14) activity was assayed by determining the oxidation of veratryl alcohol using $\mathrm{H}_{2} \mathrm{O}_{2}$ [32]. The activity of manganese peroxidase (MnP) (E.C. 1.11.1.13) was determined by monitoring the oxidation of $\mathrm{Mn}^{2+}$ using $\mathrm{H}_{2} \mathrm{O}_{2}$ [33]. Laccase (Lac) (E.C.1.10.3.2) activity was assayed by examining the oxidation of 2 'azino-bis (3-ethylbenzthiazoline-6-sulfonic acid) (ABTS) at $420 \mathrm{~nm}$ [34]. One unit activity is defined as the amount of enzyme that transformed $1 \mu \mathrm{mol}$ of substrate per min.

\section{Assay of cellulolytic enzyme activities during the degradation of tobacco stalk}

Endoglucanase (E.C.3.2.1.4) (CMCase), exoglucanase (E.C.3.2.1.91) (avicelase) and filter paper enzyme activities
(FPA) were measured spectrophoto-metrically as described by Beukes and Pletschke [35] based upon the color reaction between the degradation products (glucose) and DNS (3,5-Dinitrosalicylic acid). In all cases, one unit of enzyme activity is defined as $1 \mu \mathrm{mol}$ of glucose equivalents released per min per $\mathrm{mL}$ of filtrate under the given conditions.

\section{Additional file}

Additional file 1: The original data about the lignocellulosic content and enzyme activities detection. (XLS 3055 kb)

\section{Abbreviations}

CMCase: Endoglucanase; FPA: Filter paper enzyme; Lac: Laccase; LiP: Lignin peroxidase; MnP: Manganese peroxidase; PC: P. chrysosporium, Phanerochaete chrysosporium; TH: T. hirsute, Trametes hirsute; TV: T. versicolor, Trametes versicolor

\section{Acknowledgements}

This work was supported by the Central Research Institute of Basic Public Welfare Funds of China (2012ZL058).

\section{Funding}

This work was supported by the Central Research Institute of Basic Public Welfare Funds of China (2012ZL058)

\section{Availability of data and materials}

An original data (in excel format) about this experiment was submitted as Additional file 1, and also give an illustration about our original data in the Additional file 1

\section{Authors' contributions}

YS and HX carried out the fermentation work in this study and drafted the manuscript; SS finished the ligninolytic enzyme activities detection; CZ provide the fungi strains; SMNM carried out the cellulolytic activitie detection; JM helped the lignin cellulose content detection work; GZ detected the nicotine content; WL provide the fermentation devices and chemical materials; QW helped draft and finalise the manuscript; $\mathrm{HL}$ conducted the design of the experiment. All authors read and approved the final manuscript.

\section{Competing interests}

The authors declare that they have no competing interests.

Consent for publication

Not applicable.

Ethics approval and consent to participate

This study doesn't involve humans, human data or animals. No ethical approval was required to collect the tobacco stalk.

\section{Author details}

${ }^{1}$ Key Laboratory of Tobacco Biology and Processing, Tobacco Research Institute, Chinese Academy of Agricultural Sciences, Qingdao 266101 People's Republic of China. ${ }^{2}$ Qingdao No.9 High School, Qingdao 266012, Shandong Province, China. ${ }^{3}$ College of Agriculture and Plant Protection, Qingdao Agricultural University, Qingdao 266109, China. ${ }^{4}$ Shandong Lukang Drugs Group, Jining 272001, China.

Received: 21 October 2015 Accepted: 1 November 2016

Published online: 21 November 2016

References

1. Wang Y, Bi Y, Gao C. The assessment and utilization of straw resources in China. Agric Sci China. 2010;9(12):1807-15. 
2. Ye X, Liu H, Meng Q, Chen S, Hu Z, Sun S, Ma J, Yu X. Comparison of chemical composition in stalks of different tobaccos. Tob Sci Technol. 2013;10:76-9 (in Chinese).

3. Piotrowska-Cyplik A, Olejnik A, Cyplik P, Dach J, Czarnecki Z. The kinetics of nicotine degradation, enzyme activities and genotoxic potential in the characterization of tobacco waste composting. Bioresour Technol. 2009. 100(21):5037-44

4. Akpinar O, Erdogan K, Bakir U, Yilmaz L. Comparison of acid and enzymatic hydrolysis of tobacco stalk xylan for preparation of xylooligosaccharides. LWT-Food Sci Technol. 2010;43(1):119-25.

5. Akpinar O, Erdogan K, Bostanci S. Enzymatic production of xylooligosaccharide from selected agricultural wastes. Food Bioprod Process. 2009;87(2):145-51.

6. Kleszyk P, Ratajczak P, Skowron P, Jagiello J, Abbas Q, Frąckowiak E, Béguin F. Carbons with narrow pore size distribution prepared by simultaneous carbonization and self-activation of tobacco stems and their application to supercapacitors. Carbon. 2015;81:148-57.

7. Wu X, Xu C, Li M, Sun S, Li J, Dong W. Analysis and identification of two reconstituted tobacco sheets by three-level infrared spectroscopy. J Mol Struct. 2014;1069:133-9.

8. Wan C, Li Y. Fungal pretreatment of lignocellulosic biomass. Biotechnol Adv 2012:30(6):1447-57.

9. Yang $X$, Liu Y, Liu Z, Lai Y, Chen Y. High yield laccase producing strains screened and the study of tobacco stem degradation affected by the strains. Chinese Agr Sci Bull. 2014;30(7):52-7 (in Chinese).

10. Zhang N, Liu D, Yang $X, X u Y$, Shen Q, Huang Q. Screening of thermophilic cellulose-decomposing fungi and their efficiency in decomposing tobacco stems. Acta Sci Circumst. 2010:30(3):549-55 (in Chinese).

11. Meng XJ, Lu LL, Gu GF, Xiao M. A novel pathway for nicotine degradation by Aspergillus oryzae 112822 isolated from tobacco leaves. Res Microbiol. 2010;161(7):626-33.

12. Sanchez C. Lignocellulosic residues: biodegradation and bioconversion by fungi. Biotechnol Adv. 2009;27(2):185-94.

13. Zhong WH, Zhu CJ, Shu M, Sun KD, Zhao L, Wang C, Ye ZJ, Chen JM. Degradation of nicotine in tobacco waste extract by newly isolated Pseudomonas sp ZUTSKD. Bioresour Technol. 2010;101(18):6935-41.

14. Rathbone DA, Bruce NC. Microbial transformation of alkaloids. Curr Opin Microbiol. 2002;5(3):274-81.

15. Yu H, Guo G, Zhang X, Yan K, Xu C. The effect of biological pretreatment with the selective white-rot fungus Echinodontium taxodii on enzymatic hydrolysis of softwoods and hardwoods. Bioresour Technol. 2009;100(21):5170-5.

16. Zhang LH, Li D, Wang LJ, Wang TP, Zhang L, Chen XD, Mao ZH. Effect of steam explosion on biodegradation of lignin in wheat straw. Bioresour Technol. 2008;99(17):8512-5.

17. Eberhardt $\mathrm{H}$. The biological degradation of nicotine by nicotinophilic microorganisms. Beiträge Zur Tabakforschung. 2015;16:119-29.

18. Christian V, Shrivastava R, Modi HA, Vyas BRM. Physiology and biochemistry of lignin degradation by white-rot fungi. J Cell Tissue Res. 2004;4(1):165-78.

19. Li H, Li X, Duan Y, Zhang KQ, Yang J. Biotransformation of nicotine by microorganism: the case of Pseudomonas spp. Appl Microbiol Biotechnol. 2010;86(1):11-7

20. Zeng G-M, Zhao M-H, Huang D-L, Lai C, Huang C, Wei Z, Xu P, Li N-J, Zhang C, $L i F-L$, et al. Purification and biochemical characterization of two extracellular peroxidases from Phanerochaete chrysosporium responsible for lignin biodegradation. Int Biodeterior Biodegrad. 2013;85:166-72.

21. Bautista LF, Morales G, Sanz R. Biodegradation of polycyclic aromatic hydrocarbons (PAHs) by laccase from Trametes versicolor covalently immobilized on amino-functionalized SBA-15. Chemosphere. 2015;136: 273-80.

22. Wang F, Hu JH, Guo C, Liu CZ. Enhanced laccase production by Trametes versicolor using corn steep liquor as both nitrogen source and inducer Bioresour Technol. 2014;166:602-5.

23. Waghmare PR, Kadam AA, Saratale GD, Govindwar SP. Enzymatic hydrolysis and characterization of waste lignocellulosic biomass produced after dye bioremediation under solid state fermentation. Bioresour Technol. 2014;168: 136-41

24. Dinis MJ, Bezerra RM, Nunes F, Dias AA, Guedes CV, Ferreira LM, Cone JW, Marques GS, Barros AR, Rodrigues MA. Modification of wheat straw lignin by solid state fermentation with white-rot fungi. Bioresour Technol. 2009; 100(20):4829-35

25. Saritha M, Arora A, Nain L. Pretreatment of paddy straw with Trametes hirsuto for improved enzymatic saccharification. Bioresour Technol. 2012;104:459-65.
26. Le TMP, Eom MH, Yong HK. Inactivating effect of phenolic unit structures on the biodegradation of lignin by lignin peroxidase from Phanerochaete chrysosporium. Enzyme Microb Technol. 2014;61-62:48-54.

27. Li J, Yuan H, Yang J. Bacteria and lignin degradation. Front Biol China. 2009; 4(1):29-38.

28. Ji G, Zhang H, Huang F, Huang X. Effects of nonionic surfactant Triton X-100 on the laccase-catalyzed conversion of bisphenol A. J Environ Sci. 2009; 21(11):1486-90.

29. Zhang H, Zhang Y, Huang F, Gao P, Chen J. Purification and characterization of a thermostable laccase with unique oxidative characteristics from Trametes hirsuta. Biotechnol Lett. 2009;31(6):837-43.

30. Wang R, Han F, Yang S. Tobacco chemical quality analysis methods. Zhengzhou: Henan Science and Technology Press; 1999.

31. Van Soest PJ, Robertson JB, Lewis BA. Methods for dietary fiber, neutral detergent fiber, and nonstarch polysaccharides in relation to animal nutrition. J Dairy Sci. 1991;74(10):3583-97.

32. Tien M, Kirk TK. Lignin-degrading enzyme from Phanerochaete chrysosporium: Purification, characterization, and catalytic properties of a unique $\mathrm{H}$ (2) O (2)requiring oxygenase. Proc Natl Acad Sci U S A. 1984;81(8):2280-4.

33. Heinfling A, Martinez MJ, Martinez AT, Bergbauer M, Szewzyk U. Transformation of industrial dyes by manganese peroxidases from Bjerkandera adusta and Pleurotus eryngii in a manganese-independent reaction. Appl Environ Microbiol. 1998;64(8):2788-93.

34. Michael AP, Rosa R, Raunel T, Rafael V-D. Polycyclic aromatic hydrocarbon metabolism by white rot fungi and oxidation by Coriolopsis gallica UAMH 8260 laccase. Appl Environ Microbiol. 1999;65(9):3805-9.

35. Beukes N, Pletschke Bl. Effect of sulfur-containing compounds on Bacillus cellulosome-associated 'CMCase' and 'Avicelase' activities. Fems Microbiol Lett. 2006;264(2):226-31.

\section{Submit your next manuscript to BioMed Central and we will help you at every step:}

- We accept pre-submission inquiries

- Our selector tool helps you to find the most relevant journal

- We provide round the clock customer support

- Convenient online submission

- Thorough peer review

- Inclusion in PubMed and all major indexing services

- Maximum visibility for your research

Submit your manuscript at www.biomedcentral.com/submit 